\title{
Publisher Correction: The cost of mitigation revisited
}

Alexandre C. Köberle (D), Toon Vandyck (D), Celine Guivarch (1), Nick Macaluso, Valentina Bosetti(i), Ajay Gambhir(D), Massimo Tavoni and Joeri Rogelj

Correction to: Nature Climate Change https://doi.org/10.1038/s41558-021-01203-6, published online 11 November 2021.

In the version of the article originally published, a processing error affected the graphics presented in Fig. $2 \mathrm{a}$ and 3 . For Fig. $2 \mathrm{a}$, "Consumption as cost metric". The original and corrected versions are shown below, and the article has been updated with the revised version. For Fig. 3, the two arrows on the bottom right have now been amended to include dark-shaded tips to representing impacts of earlier action. The changes have been made to the online versions of the article.

\section{Original}

a

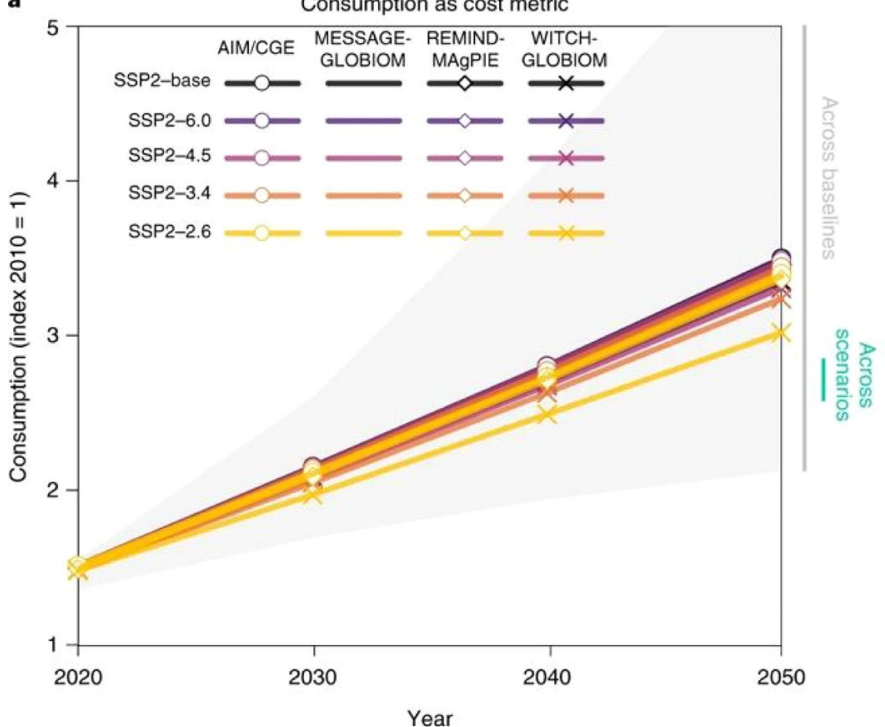

Corrected

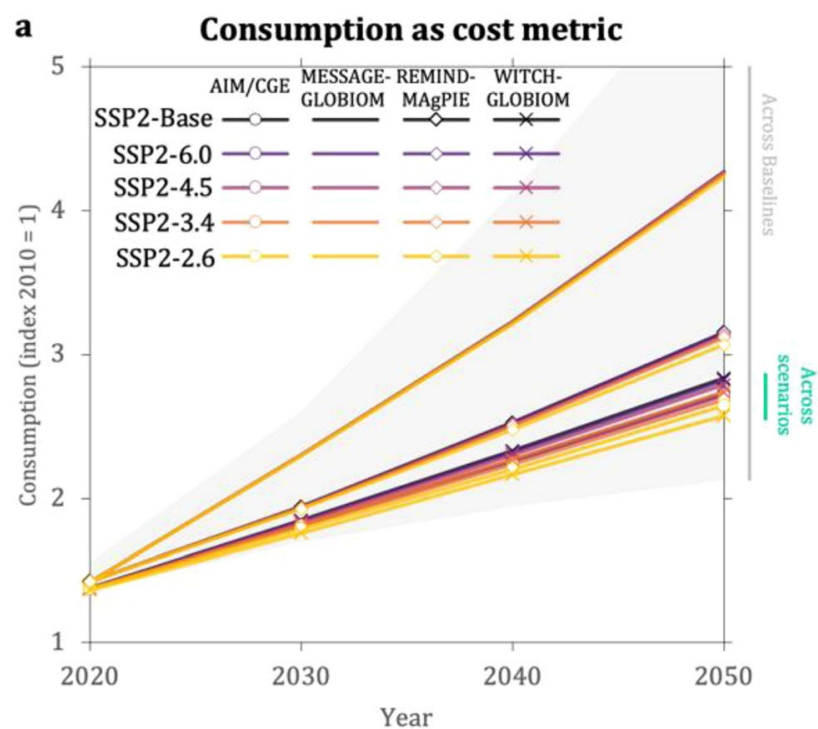

Fig. 2 | Original and Corrected.

Published online: 29 November 2021

https://doi.org/10.1038/s41558-021-01252-X

(c) The Author(s), under exclusive licence to Springer Nature Limited 2021 